\title{
PROBLEMA DE PROGRAMAÇÃO LINEAR DA DIETA APLICADO À NUTRIÇÃO DE SUÍNOS
}

\author{
Marcos dos Santos* \\ Renato Santiago Quintal**
}

\begin{abstract}
RESUMO: A Programação Linear caracteriza-se como uma técnica de otimização voltada para a solução de modelos descritos por equações lineares, beneficiandose da capacidade crescente de processamento dos computadores. O artigo em tela representa um problema de programação linear clássico, formulado a partir de informações do setor suinocultor brasileiro. Nesse sentido, o objetivo do presente estudo é propor uma ração com valores nutricionais adequados e de reduzido custo de produção. Por ocasião da implementação da referida dieta, o tomador de decisão deverá ter em mente de que está diante de um sistema dinâmico, em que os insumos são afetados o tempo todo por distintas variáveis, de difícil modelagem, o que certamente demandará do gestor criatividade e flexibilidade.
\end{abstract}

PALAVRAS-CHAVE: Agronegócio; Ciências agrárias; Dieta de suínos; Programação linear.

\section{PROBLEMS IN LINEAR PROGRAMS FOR DIETS APPLIED TO SWINE NUTRITION}

ABSTRACT: Linear programming is an optimizing technique for the solution of models described by linear equations through the growing capacity of computer processing. Current paper provides a problem in classic linear programming formulated from information by the Brazilian swine sector. Current study proposes a diet with adequate nutritional rates at reduced production costs. Managers for the implementation of the diet should have in mind that they are dealing with a dynamic system in which fertilizations are affected over time by several variables, with difficult modeling, with a greater deal of creativity and flexibility on the manager's part.

KEY WORDS: Agribusiness; Agrarian Sciences; Swine Diets; Linear Programming.

\footnotetext{
Doutorando em Engenharia de Produção (Modelagem no Apoio à Decisão) pela Universidade Federal Fluminense (UFF), Rio de Janeiro, Brasil.

** Mestre em Ciências Contábeis pela Faculdade de Administração e Finanças da Universidade do Estado do Rio de Janeiro (UERJ), Rio de Janeiro, Brasil. E-mail: rsantiago79@hotmail.com
} 


\section{INTRODUÇÃO}

A Programação Linear (PL) caracteriza-se como uma técnica de otimização voltada para a solução de modelos descritos por equações lineares, beneficiando-se da capacidade crescente de processamento dos computadores (FARIAS, 2013, p. 9).

Corrar, Teóphilo e Bergmann (2004, p. 331) afirmam que a Programação Linear é uma das mais relevantes ferramentas da seara da Pesquisa Operacional: representa uma área do conhecimento que disponibiliza um agregado de procedimentos orientados ao tratamento de problemas que contemplam a escassez de recursos. Nesse contexto, podem ser solucionados com o emprego da PL os problemas nos quais se almeja a melhor distribuição de recursos, de modo a se alcançar determinado objetivo de otimização, observando determinadas restrições. Tratam-se de limitações que podem estar associadas ao montante ou à maneira de se distribuir os recursos.

Segundo Xavier (2013, p. 32), durante a Segunda Guerra Mundial, a pesquisa encontrava-se concentrada em dois ramos particulares, a saber: Operations Evaluation Group, ligado à Marinha, e o Statistical Research Group, associado à Força Aérea. No primeiro, a Teoria dos Jogos identifica a sua inaugural aplicação militar; no segundo, observa-se a formação de um grupo de matemáticos do pósguerra focado no projeto RAND, orientado à pesquisa em jogos e aos estudos em aplicações militares.

Para Getirana (2005, p. 57), o desenvolvimento simultâneo de duas técnicas na primeira metade do século XX fomentou o desenvolvimento da PL. A primeira contribuição foi dada por John Von Newman, por ocasião da publicação do Teorema Central da Teoria dos Jogos, nos idos de 1928 (VON NEUMAN, 1928), que posteriormente foi elaborada por meio da PL e interpretada à luz da Teoria da Dualidade. A segunda contribuição foi verificada em 1936 e deve-se à elaboração da análise input-output, estruturada a partir de um modelo matricial linear, o qual, em um segundo momento, veio a ser empregado sob a apresentação de um Problema de Programação Linear (PPL), formulado por Leontief (LEONTIEF, 1936).

Mirshawka (1972 apud Menon, 2005, p. 9) destaca que dentre os pioneiros 
do modelo de PL identificados na literatura, são dignos de realce os seguintes pesquisadores: Von Newman, que formulou em 1928 o arcabouço conceitual sobre o emprego do teorema de mínimo-máximo aos jogos de estratégia; Hitchcock, que concebeu o problema de transporte, desenvolvido de forma independente por Koopmans, em 1947; e, por fim, Stingler, que concebeu o problema da dieta em 1945.

A PPL desenvolveu-se teoricamente após a Segunda Guerra Mundial, a partir dos estudos do soviético Kolmogorov com o propósito de solucionar problemas relacionados à logística militar. O grande marco na evolução das pesquisas em PL foi verificado em 1947, com a formulação pelo jovem matemático George Bernard Dantzig do método denominado "método simplex". Dantzig, matemático da Força Aérea norte americana e em contato com aspectos afetos à logística, vislumbrou que problemas que contemplavam escassez de recursos podiam ser solucionados a partir de uma sistemática de busca de solução ótima entre uma coleção de possíveis soluções (CORRAR; TEÓPHILO; BERGMANN, 2005, p. 332). Getirana (2005, p. 57) argumenta que teve início uma época de veloz desenvolvimento e aplicações a problemas de gerenciamento da produção, os quais anteriormente eram solucionados por meio da experiência e indução.

A primeira solução exitosa de PPL de grande porte foi verificada em 1952 em um computador instalado no National Bureau of Standards e, um ano depois, quando os computadores passaram a ser fabricados em linha, houve a possibilidade de se iniciar o processo de popularização da técnica, com praticamente todos os computadores associados a uma rotina de PL de simples utilização e compreensão, consistindo em um dos instrumentos mais amplamente utilizados. $\mathrm{O}$ aparecimento de pacotes computacionais de PL para sistemas informatizados e a incorporação da ferramenta Solver ao Microsoft Excel assumiram uma relevante atribuição na disseminação da técnica (GETINANA, 2005, p. 57).

$\mathrm{O}$ acelerado progresso dos computadores contribuiu para que a PL passasse a ser empregada como ferramenta de gestão empresarial. Tanto que o russo Kantorovich conquistou o Prêmio Nobel em Economia pela elaboração de conceitos de planejamento ótimo. Em 1984, Karmakar formulou um algoritmo que tem se apresentado superior ao simplex para a solução de problemas sensivelmente robustos. Apesar disso, o método simplex permanece sendo o mais aplicado na 
atualidade, inclusive como suporte lógico das planilhas eletrônicas.

$\mathrm{O}$ artigo em tela representa um problema de programação linear clássico, formulado a partir de informações do setor suinocultor brasileiro. Nesse sentido, o objetivo do presente estudo é propor uma ração com valores nutricionais adequados a um menor custo possível.

Para Roppa (2002), as atividades afetas à suinocultura situam-se em posição privilegiada na matriz produtiva do agronegócio no Brasil, apresentando relevância no plano econômico e social do país. Estima-se que um quantitativo superior a 730 mil pessoas dependem frontalmente da suinocultura, sendo uma atividade responsável pela geração de renda a mais de 2,7 milhões de indivíduos. Nesse contexto, Gonçalves e Palmeira (2006) acrescentam que a suinocultura não contribui somente por meio das articulações econômicas internas, mas igualmente por intermédio da geração de divisas no comércio internacional.

Alves (2007) destaca que o incremento do consumo da carne suína é verificado anualmente, especialmente pelas boas condições do produto entregue ao consumidor. Nessas circunstâncias, uma adequada formulação da ração poderá contribuir para o oferecimento de uma carne com excelentes qualidades ao consumidor.

O estudo é composto pelas seguintes seções: O setor da suinocultura no Brasil; A modelagem do problema e a formulação da ração; e Considerações finais.

\section{O SETOR DA SUINOCULTURA NO BRASIL}

Essa seção é composta pelas seguintes subseções: Contexto qualitativo da suinocultura; Exigências nutricionais para suínos; e Contextos quantitativos da suinocultura.

\subsection{CONTEXTO QUALITATIVO DA SUINOCULTURA}

Segundo pesquisa de Roppa (2008 apud DI CAMPOS, 2010, p. 18), o Brasil é detentor do terceiro maior rebanho mundial de suínos com números superiores 
a 32 milhões de unidades, suplantado unicamente pelos Estados Unidos da América e pela China, os quais apresentam 60 milhões e 460 milhões de animais, respectivamente. As informações mais recentes afetas ao Censo Agropecuário, disponíveis na página do Instituto Brasileiro de Geografia e Estatística (IBGE) na Internet, remontam ao ano de 2013 e reportam o Brasil como o detentor de um rebanho suíno de 36.743.593 de cabeças.

O crescimento do rebanho de suínos no Brasil tem se mantido praticamente constante, enquanto que o número de matrizes suínas decresceu nos últimos dez anos. Por outro lado, a produção de leitões cresceu significativamente, passando de 22,4 milhões em 1993 para quase 30 milhões em 2002 (GARCIA; PALMEIRA, 2006).

Isso reflete os avanços em tecnologias de produção implementados nesse período, o que permitiu aumentar significativamente a produtividade do plantel de matrizes. Um indicador representativo desse avanço é o número de leitões/ matriz/ano: em 1993 a média era de 7 leitões/matriz, passando para 9,8 em 2002 (ANUALPEC, 2002).

Em 2001, a produção brasileira foi de 2.117 mil toneladas, e a posição entre os maiores produtores passou para $6^{\mathrm{a}}$, com uma produção equivalente a mais de $2,5 \%$ da produção mundial. Nesse período, em relação aos doze maiores produtores, o Brasil foi o que obteve o maior aumento na produção, aproximando-se de $70 \%$ (ANUALPEC, 2002).

\subsection{EXIGÊNCIAS NUTRICIONAIS PARA SUÍNOS}

Segundo informações da Associação Brasileira de Criadores de Suínos, referentes ao ano de 2006, disponíveis na pesquisa de Levandoscki (2007, p. 6), levando-se em consideração os custos envolvidos na criação de suínos no Brasil, em média, $65 \%$ do custo de produção é composto pela alimentação em granjas estabilizadas e de ciclo completo. Sabendo-se disso e buscando-se auferir lucros maiores no segmento suinocultor, Levandoscki $(2007$, p. 6) ressalta a necessidade da formulação de um planejamento adequado voltado para a alimentação dos animais. Neste escopo, está incluída a disponibilização de rações balanceadas, que contemplem os nutrientes essenciais para que os animais sejam capazes de manifestar 
todo o seu potencial genético e exibirem um bom desempenho produtivo.

Em épocas de crise na atividade o valor atinge a cifra de 70 a $75 \%$. Isto significa, por exemplo, que se a conversão alimentar de rebanho for de 3,1 e a alimentação representar $70 \%$ dos custos de produção, a equivalência mínima entre preços deverá ser de 4,4 (o preço do suíno deverá ser no mínimo 4,4 vezes superior ao preço da ração) para que o produtor equilibre os custos de produção com o preço de venda dos animais. Neste aspecto a possibilidade de auferir lucros com a suinocultura depende fundamentalmente de um adequado planejamento da alimentação dos animais. Isso envolve a disponibilidade de ingredientes em quantidade e qualidade adequada a preços que viabilizem a produção de suínos (EMBRAPA, 2010).

A obtenção de lucros também exige a combinação adequada dos ingredientes para compor dietas balanceadas nutricionalmente, para cada fase de produção, visando atender as exigências nutricionais específicas.

A aplicação dos conhecimentos de nutrição deve contribuir para a preservação do ambiente e isto significa que o balanceamento das rações deve atender estritamente as exigências nutricionais nas diferentes fases de produção. $\mathrm{O}$ excesso de nutrientes nas rações é um dos maiores causadores de poluição do ambiente, portanto, atenção especial deve ser dada aos ingredientes, buscando-se aqueles que apresentam alta digestibilidade, disponibilidade dos nutrientes e que sejam processados adequadamente (BELLAVER; LUDKE, 2004).

Para Maynard e Loosli (1984), a eficiência dos animais como produtores de alimentos - leite, ovos, carne - estabelece uma relação de dependência, essencialmente, com a sua capacidade genética e do ambiente. Em se tratando de ambiente, convém destacar as seguintes variáveis: clima, sanidade, alimentação e manejo das instalações, dos animais, da alimentação. A adequada nutrição com uma ração balanceada e o ajustado manejo alimentar permitirão que o animal converta com eficiência os nutrientes dos alimentos em produção, conforme idade e finalidade. Para que essa conversão seja eficiente, faz-se necessário que o animal apresente um potencial genético a ser manifestado. Somem-se a isso o manejo e a higiene para a prevenção de doenças e para o oferecimento de condições básicas à criação animal.

Os animais não devem ser expostos, via alimentação e água, a produtos 
químicos ou agentes biológicos que sejam prejudiciais para a produção e reprodução. No contexto do bem-estar animal, a nutrição deve assegurar o aporte adequado de nutrientes para a manutenção normal da gestação, para a ocorrência de partos normais e para uma produção adequada de leite que garanta um desenvolvimento normal dos leitões durante o período de lactação (EMBRAPA, 2010).

Segundo Ferreira (2000), o cálculo de rações para suínos em um contexto de países tropicais encontra-se baseado em parâmetros estabelecidos em países temperados. Sendo assim, nem sempre é alcançada a performance esperada, especialmente em razão da temperatura ambiente, que pode ocasionar transtornos metabólicos e fisiológicos aos animais. Contudo, verifica-se um hiato de informações na literatura nacional afeta à inter-relação nutrição e ambiente.

Para Ferreira (2009), o ambiente térmico influencia o consumo de ração, a taxa de eficiência e o ganho de peso dos suínos, provocando assim, modificação na composição de sua carcaça. Em ambiente frio, os suínos aumentam o consumo de ração, devido à maior demanda de energia, numa tentativa de manter a homeotermia. Desta forma, grande parte dos nutrientes ingeridos será direcionada para mantença e o restante será utilizado para o crescimento efetivo do suíno.

Os diferentes regimes nutricionais, associados às variações ambientais, às quais os suínos estão sujeitos, provocam diversificação nas respostas dos mesmos. Desta forma, ao otimizar a utilização dos alimentos que o suíno ingere, há necessidade de determinar os limites das condiçóes ambientais, nos quais o gasto de energia seja mínimo (FERREIRA, 2009).

Segundo Bellaver e Ludke (2004), a indústria nacional de alimentação animal emprega aproximadamente $60 \%$ da produção de milho e $20 \%$ do país. Os autores em tela referenciam informações do ano de 2003, extraídas do Sindicato Nacional da Indústria de Alimentação Animal (SINDIRAÇÕES), as quais evidenciam que a demanda de ingredientes para a produção de rações em todo o território nacional oscila em aproximadamente 44 milhões de toneladas.

Lima (1996 apud MARCATO; LIMA, 2006, p. 150) argumenta que o segmento suinocultor brasileiro vem vivenciando sensíveis transformações tecnológicas nos últimos anos, com vistas a elevar a sua produtividade e reduzir os custos de produção. Para Girotto (1989), a alimentação representa um dos principais fatores que encarecem o custo de produção de suínos, concorrendo para, aproximadamente, 
70 a $75 \%$ do custo total médio.

Segundo Fávero et al. (2003), promovendo-se a avaliação da série histórica dos custos de produção de suínos no Brasil, em média, observa-se que a alimentação das granjas estabilizadas e de ciclo completo representa $65 \%$ do custo. Em períodos de crise na atividade, o valor atinge a marca de 70 a $75 \%$. Isso significa, por exemplo, que se a conversão alimentar do rebanho - razão entre a massa de ração consumida em Kg e a massa de animais vendidos no mesmo período em $\mathrm{Kg}$ - for de 3,1 e alimentação representar $70 \%$ dos custos de produção, a equivalência mínima entre os preços necessitará ser de 4,4, ou seja, o preço do suíno deverá ser minimamente 4,4 vezes superior ao preço da ração. Nesse contexto, a possibilidade de obter lucros com a suinocultura depende essencialmente de um efetivo planejamento da alimentação dos animais, contemplando a disponibilidade de ingredientes em quantidade e qualidade adequada a valores financeiros que propiciem a produção de suínos.

Para Fávero et al. (2003), o auferimento de lucros igualmente demanda o arranjo adequado dos ingredientes necessários à composição das dietas balanceadas nutricionalmente para cada etapa da produção, com vistas ao atendimento das exigências nutricionais determinadas. Em média, em uma granja estabilizada de ciclo completo, para cada porca do plantel produzindo 20 leitões anualmente, encerrados os $105 \mathrm{~kg}$ de massa para o abate, existe a necessidade de dispor de 7.000 $\mathrm{kg}$ de ração, com um desembolso médio de $240 \mathrm{~kg}$ de núcleo, $5.260 \mathrm{~kg}$ de milho e $1.500 \mathrm{~kg}$ de farelo de soja. Adicionalmente, considerando-se uma relação média de 2,8 litros de água potável para cada $\mathrm{kg}$ de ração consumida, presume-se um gasto anual de 19,6 mil litros de água potável para cada porca e sua produção.

Nesse contexto de elevados custos de produção, os pequenos produtores acabam se vendo obrigados a reduzir o plantel ou abater com menor peso os animais, soluções vistas como imediatas, antigas e recorrentes. Contudo, não são as melhores. O custo de produção é fortemente dependente da alimentaçãa e a solução possivelmente esteja em otimizá-la. Os serviços de extensão rural oficiais necessitam estar preparados para informar sobre culturas alternativas de inverno (trigo, triticale, cevada), de verão (sorgo e milho) e contínuas (tubérculos de mandioca) (EMBRAPA, 2010).

Para Zanotto (1999), entre os ingredientes utilizados nas rações para 
suínos, o milho representa a maior porcentagem (70\%) e também é o elemento de maior susceptibilidade à granulometria. A qualidade da ração está diretamente ligada ao controle do processo de moagem do milho, pois a digestibilidade de todos os nutrientes presentes nos grãos é proporcionada pela granulometria correta. $\mathrm{O}$ resultado será o melhor desempenho produtivo dos animais.

Segundo argumenta Zanotto (1999), a granulometria refere-se às dimensões dos macroingredientes empregados no processo de fabricação das rações e igualmente às medidas das próprias rações. Outrossim, a granulometria da ração é fruto da granulometria dos ingredientes que a integram. A eficiência dos alimentos está frontalmente associada à granulometria, pois uma vez que os ingredientes não atendem a determinadas especificações, uma sucessão de problemas pode ser desencadeada, desde a má formação da ração até o mau aproveitamento por parte dos animais. Nessas circunstâncias, os suinocultores necessitam sempre estar cautelosos aos alimentos oferecidos aos animais em relação à granulometria.

\subsection{CONTEXTOS QUANTITATIVOS DA SUINOCULTURA}

Segundo Zardo e Lima (1999, p. 16), o cálculo da quantidade de cada ingrediente que faz parte da composição de uma ração, com base na sua constituição química e nas demandas nutricionais da categoria de animais a que a ração é destinada, denomina-se formulação de ração. A eleição dos alimentos e a proporção com que cada um integra a ração depende do balanceamento de nutrientes almejado. Devem ser consideradas, igualmente, as restrições existentes em alguns ingredientes, como, por exemplo, problemas de toxidade, manuseio, conservação e, especialmente, o seu custo.

Zardo e Lima (1999, p. 16) afirmam que, usualmente, as rações são calculadas a partir do custo mínimo, levando-se em consideração um valor médio para a composição química dos alimentos. Contudo, outros atributos estão cada vez mais sendo considerados, como, por exemplo, a variabilidade na composição química dos ingredientes, as diferenças genéticas dos suínos e o máximo ganho esperado.

Existem várias técnicas para o cálculo das rações. Até pouco tempo, as 
mais usadas eram o quadrado de Pearson e o sistema de equações, com o uso de calculadoras. Atualmente, com o avanço da informática, tornou-se usual o emprego de programas de computadores que usam a programação linear para o cálculo (EMBRAPA, 2010).

A ração apresentada leva em conta suínos na fase de crescimento; as exigências nutricionais estão expostas na Tabela 1 .

Tabela 1. Alimentos e quantidades necessárias para uma nutrição equilibrada de suínos

\begin{tabular}{ccccccc}
\hline Alimentos & PB (\%) & $\begin{array}{c}\text { EM (Kcal/ } \\
\mathbf{k g})\end{array}$ & $\begin{array}{c}\text { Ca } \\
\mathbf{( \% )}\end{array}$ & $\begin{array}{c}\text { P Total } \\
\mathbf{( \% )}\end{array}$ & $\begin{array}{c}\text { Lisina } \\
\mathbf{( \% )}\end{array}$ & $\begin{array}{c}\text { Custo/kg } \\
\mathbf{( R \mathbf { ~ } )}\end{array}$ \\
\hline Milho & 8,51 & 3.493 & 0,02 & 0,27 & 0,23 & 0,29 \\
Farinha de soja & 45,6 & 3.378 & 0,36 & 0,55 & 2,87 & 0,67 \\
Farinha de trigo & 15,3 & 2.103 & 0,12 & 0,88 & 0,57 & 0,32 \\
Farinha de carne & 45,2 & 2.133 & 11,6 & 5,4 & 2,28 & 1,2 \\
Farinha de sangue & 80,9 & 2.809 & 0,2 & 0,15 & 6,57 & 1,44 \\
Fosfato Bicálcico & - & - & 22,61 & 17,03 & - & 2,32 \\
Calcário & - & - & 37 & - & - & 0,13 \\
Sal & - & - & - & - & - & 0,48 \\
Mistura mineral & - & - & - & - & - & 4,48 \\
Mistura vitamínica & - & - & - & - & - & 23,2 \\
\hline
\end{tabular}

Fonte: (EMBRAPA, 2011).

Para que se alcance o objetivo esperado, que é fornecer uma nutrição equilibrada, deve-se preparar uma ração para suínos em crescimento respeitando as quantidades máximas e mínimas de cada alimento, conforme pode ser evidenciado nas Tabelas 2 e 3, abaixo transcritas. 
Tabela 2. Níveis de garantia, aditivos e alimentos empregados na ração de suínos

\begin{tabular}{l|c|l|c|l|l}
\hline \multicolumn{2}{c|}{ Níveis de Garantia } & \multicolumn{2}{c|}{ Aditivos } & \multicolumn{2}{c}{ Alimento } \\
\hline & $\%$ & & $\%$ & & $\%$ \\
\hline Prot. Bruta (PB) (Máx.) & 16,0 & Mistura 1 & 0,1 & Farinha de soja & 15,85 \\
Cálcio (Ca) (Mín.) & 0,65 & Mistura 2 & 0,1 & Farinha de carne & 1,29 \\
Fósforo Total (P) (Mín.) & 0,5 & Sal comum & 0,5 & Farinha de sangue & 1,29 \\
Energ. Met. (EM) (Máx.) & 3.360 & Fosfato bicálcico & 0,49 & Milho & 69,99 \\
Lisina (Mín.) & 0,69 & Calcário & 0,81 & Farinha de trigo & 7,78 \\
& & Óleo de soja & 1,78 & & \\
\hline & & Total & $\mathbf{3 , 8 0}$ & Total & $\mathbf{9 6 , 2 0}$ \\
\hline
\end{tabular}

Fonte: (EMBRAPA, 2011)

A Tabela 3, abaixo transcrito, exibe os percentuais de mistura energética, proteica e alimento empregados na ração de suínos.

Tabela 3. Percentuais de mistura energética e proteica e alimento empregados na ração de suínos

\begin{tabular}{|l|c|c|c|}
\hline Mistura Energética & PB (\%) & \% Alimento & PB (\%) \\
\hline Milho & 8,51 & 90 & 7,66 \\
\hline Farinha de trigo & 15,3 & 10 & 1,53 \\
\hline Total & - & - & $\mathbf{9 , 1 9}$ \\
\hline Mistura Proteica & PB (\%) & \% Alimento & PB (\%) \\
\hline Farinha de soja & 45,6 & 86 & 39,22 \\
\hline Farinha de carnes & 45,2 & 7 & 3,16 \\
\hline Farinha de sangue & 80,9 & 7 & 5,66 \\
\hline Total & - & - & $\mathbf{4 8 , 0 4}$ \\
\hline
\end{tabular}

Fonte: (EMBRAPA, 2011).

Por meio de conceitos de programação linear e métodos de estruturação de problemas, vislumbra-se a possibilidade de formulação de um modelo matemático 
que atenda as necessidades apresentadas no presente estudo.

\section{PROGRAMAÇÃO LINEAR USANDO O SOFTWARE LINGO}

Para Almeida; Martins e Silva (2013), a programação linear tem sido uma técnica empregada com frequência para resolver problemas distintos, especialmente relacionados à maximização de rendimento e lucro e minimização de gastos no processo.

O Lingo é um software interativo para resolução de problemas de programação linear, quadrática, inteira e não-linear. O algoritmo utilizado pelo Lingo é superior ao utilizado pelo Excel, tornando sua solução mais eficiente, rápida e segura. Além disso, pode ser empregado para resolução de problemas reais com mais de dez mil variáveis. A Tabela 4 abaixo evidencia a quantificação dos alimentos a partir da inserção de dados no software Lingo.

Tabela 4. Quantificação dos alimentos a partir da inserção de dados no software Lingo

\begin{tabular}{cccccccc}
\hline \multirow{2}{*}{ Variável } & Alimento & Proteína & Energia & Cálcio & Fósforo & Lisina & Preço \\
\cline { 3 - 7 } & & $\mathbf{( \% )}$ & $\mathbf{( k c a l / k g )}$ & $\mathbf{( \% )}$ & $\mathbf{( \% )}$ & $\mathbf{( \% )}$ & $\mathbf{( R \mathbf { k g } )}$ \\
\hline X3 & Farinha de trigo & 15,3 & 2.103 & 0,12 & 0,88 & 0,57 & 0,32 \\
X6 & Fosfato bicálcico & & & 22,61 & 17,03 & & 2,32 \\
X7 & Calcário & & 37 & & & 0,13 \\
X8 & Sal & & & & & 0,48 \\
X9 & Mistura mineral & & & & & 4,48 \\
X10 & Mistura & & & & & 23,2 \\
\hline
\end{tabular}

Fonte: Elaborado pelos autores.

Faz-se necessário destacar que, na Tabela 4 acima transcrito, foram selecionados apenas os ingredientes para os quais o software Lingo gerou valores.

Nesse contexto, a Tabela 5 apresentado abaixo exibe os valores gerados pelo software Lingo, bem como os cálculos associados ao quantitativo de cada item disponibilizado pelo software para a composição final da ração. 
Tabela 5. Quantitativo de cada item fornecido pelo Lingo para a composição final da ração

\begin{tabular}{|c|c|c|c|c|c|c|}
\hline $\begin{array}{l}\text { Quant. } \\
\text { fornecida pelo } \\
\text { Lingo }\end{array}$ & Proteína & Energia & Cálcio & Fósforo & Lisina & Preço \\
\hline (kg) & (\%) & (kcal/kg) & (\%) & (\%) & (\%) & $(\mathrm{R} \$ / \mathrm{kg})$ \\
\hline 1,597718 & 0,2445 & 3.360 & 0,001917 & 0,0140599 & 0,009107 & 0,51 \\
\hline 2,970875 & 0,0000 & 0 & 0,671715 & 0,50594 & 0 & 6,89 \\
\hline 94,73141 & 0,0000 & 0 & 35,05062 & 0 & 0 & 12,32 \\
\hline 0,5 & 0,0000 & 0 & 0 & 0 & 0 & 0,24 \\
\hline 0,1 & 0,0000 & 0 & 0 & 0 & 0 & 0,45 \\
\hline \multirow[t]{4}{*}{0,1} & 0,0000 & 0 & 0 & 0 & 0 & 2,32 \\
\hline & Proteína & Energia & Cálcio & Fósforo & Lisina & Preço \\
\hline & (\%) & (kcal/kg) & (\%) & (\%) & (\%) & $(\mathrm{R} \$ / \mathrm{kg})$ \\
\hline & 0,244450854 & 3.360 & 35,72425 & 0,5199999 & 0,009107 & 22,73 \\
\hline
\end{tabular}

Fonte: Elaborado pelos autores.

Em última análise, as Tabelass 5 e 6 exibem a diferença entre o que necessitaria estar contemplado na ração e o que efetivamente haverá. Em relação à proteína, observa-se que o valor está aquém do previsto; em sentido contrário, o cálcio integra em abundância a relação em tela. Trata-se de uma ração cuja composição é formada majoritariamente pelo cálcio, com baixa presença de lisina e fósforo. Nesse contexto, menção especial deve ser feita ao elevado custo por Kg de ração.

Tabela 6. Composição mínima e máxima e diferenças de ingredientes da ração de suínos

\begin{tabular}{ccccc} 
& & & \multicolumn{2}{c}{ Diferença } \\
\cline { 3 - 5 } Item & Mínimo & Máximo & Mínimo & Máximo \\
\hline Proteína & 15,5 & 16 & $-15,25555$ & $-15,75555$ \\
Energia (Kcal/Kg) & 3.260 & 3.360 & 100 & 0 \\
P (\%) & 0,5 & 0,52 & 0,02 & $-6,91 \mathrm{E}-08$ \\
Ca (\%) & 0,65 & 0,782 & 35,07425 & 34,942254 \\
Lisina (\%) & 0,69 & s/limite & $-0,680893$ & - \\
\hline
\end{tabular}


Fonte: Elaborado pelos autores.

\section{FORMULAÇÃO IDEAL DA RAÇÃO}

A presente seção objetiva mostrar passo a passo o processo de formulação ideal da ração. A Tabela 7 abaixo transcrita apresenta a memória de cálculo envolvendo as misturas energética e proteica na formulação da ração.

Tabela 7. Memória de cálculo envolvendo as misturas energética e proteica na formulação da ração

\begin{tabular}{lcccc}
\hline Mistura Energética & PB (\%) & \% Alimento & Cálculo & Resultado PB (\%) \\
\hline Milho & 8,51 & 90 & $8,51^{*}(90 / 100)$ & 7,66 \\
Farinha de trigo & 15,3 & 10 & $15,3^{*}(10 / 100)$ & 1,53 \\
Total & - & - & - & $\mathbf{9 , 1 9}$ \\
\hline Mistura Proteica & PB (\%) & \% Alimento & Cálculo & PB (\%) \\
\hline Farinha de soja & 45,6 & 86 & $45,6^{*}(86 / 100)$ & 39,22 \\
Farinha de carne & 45,2 & 7 & $45,2^{*}(7 / 100)$ & 3,16 \\
Farinha de sangue & 80,9 & 7 & $80,9^{*}(7 / 100)$ & 5,66 \\
\hline Total & - & - & - & $\mathbf{4 8 , 0 4}$ \\
\hline
\end{tabular}

Fonte: Elaborado pelos autores.

A Figura 1 lançada abaixo apresenta o Quadrado de Pearson, também conhecido como Quadrado de Misturas, que tem a função de determinar os percentuais em que cada um dos alimentos deve ser misturado, de modo a se obter uma mistura com determinadas características.

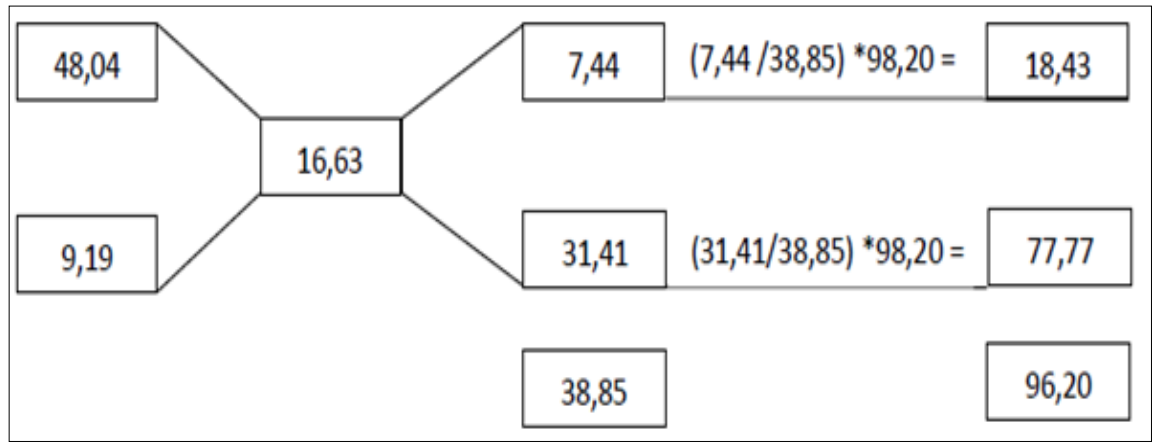

Figura 1. Quadrado de Pearson 
Fonte: Elaborado pelos autores.

Convém destacar que o Quadrado de Pearson acima transcrito subsidiou a formulação da Tabela 8 abaixo, que apresenta a nova distribuição das misturas energética e proteica.

Tabela 8. Nova distribuição das misturas energética e proteica após a formulação do Quadrado de Pearson

\begin{tabular}{lcccc}
\hline Mistura Energética & PB (\%) & \% Alimento & Cálculo & Resultado PB (\%) \\
\hline Milho & 77,77 & 90 & $77,77^{*}(90 / 100)$ & 69,99 \\
Farinha de trigo & 77,77 & 10 & $77,77^{*}(10 / 100)$ & 7,78 \\
\hline Subtotal & - & - & - & $\mathbf{7 7 , 7 7}$ \\
\hline Mistura Proteica & PB (\%) & \% Alimento & Cálculo & PB (\%) \\
\hline Farinha de soja & 18,43 & 86 & $18,43^{*}(86 / 100)$ & 15,85 \\
Farinha de carne & 18,43 & 7 & $18,43^{*}(7 / 100)$ & 1,29 \\
Farinha de sangue & 18,43 & 7 & $18,43^{*}(7 / 100)$ & 1,29 \\
\hline Subtotal & - & - & - & $\mathbf{1 8 , 4 3}$ \\
\hline Total & - & - & & $\mathbf{9 6 , 2}$ \\
\hline
\end{tabular}

Fonte: Elaborado pelos autores.

A Tabela 9 abaixo apresenta a distribuição de Cálcio nas misturas energética e proteica.

Tabela 9. Distribuição de Cálcio nas misturas energética e proteica

\begin{tabular}{lcccc}
\hline Mistura Energética & Ca (\%) & \% Alimento & Cálculo & Resultado Ca (\%) \\
\hline Milho & 0,02 & 69,99 & $\begin{array}{c}0,02^{*} \\
(69,99 / 100)\end{array}$ & 0,0140 \\
Farinha de trigo & 0,12 & 7,78 & $0,12 *(7,78 / 100)$ & 0,0093 \\
Subtotal & - & - & - & $\mathbf{0 , 0 2 3 3}$ \\
\hline Mistura Proteica & PB (\%) & \% Alimento & Cálculo & Resultado Ca (\%) \\
\hline Farinha de soja & 0,36 & 15,85 & $\begin{array}{c}0,36^{*} \\
(15,85 / 100)\end{array}$ & 0,0571 \\
Farinha de carne & 11,60 & 1,29 & $\begin{array}{c}11,60^{*} \\
(1,29 / 100)\end{array}$ & 0,1496 \\
Farinha de sangue & 0,20 & 1,29 & $0,20^{*}(1,29 / 100)$ & 0,0026 \\
\hline Subtotal & - & - & - & $\mathbf{0 , 2 0 9 3}$ \\
\hline
\end{tabular}




\begin{tabular}{l} 
Total $\quad \cdot-100$ \\
\hline Fonte: Elaborado pelos autores. \\
A Tabela 10 abaixo ilustra a distribuição de Fósforo total nas misturas \\
energética e protéica.
\end{tabular}

Tabela 10. Distribuição de Fósforo total nas misturas energética e proteica

\begin{tabular}{lcccc}
\hline Mistura Energética & PT (\%) & \% Alimento & Cálculo & Resultado PT (\%) \\
\hline Milho & 0,27 & 69,99 & $0,27^{*}(69,99 / 100)$ & 0,1890 \\
Farinha de trigo & 0,88 & 7,78 & $0,88^{*}(7,78 / 100)$ & 0,0684 \\
Subtotal & - & - & - & $\mathbf{0 , 2 5 7 4}$ \\
\hline Mistura Proteica & PB (\%) & \% Alimento & Cálculo & Resultado PT (\%) \\
\hline Farinha de soja & 0,55 & 15,85 & $0,55^{*}(15,85 / 100)$ & 0,0872 \\
Farinha de carne & 5,40 & 1,29 & $5,40^{*}(1,29 / 100)$ & 0,0697 \\
Farinha de sangue & 0,15 & 1,29 & $0,15^{*}(1,29 / 100)$ & 0,0019 \\
\hline Subtotal & - & - & - & $\mathbf{0 , 1 5 8 8}$ \\
\hline Total & - & - & - & $\mathbf{0 , 4 1 6 2}$ \\
\hline
\end{tabular}

Fonte: Elaborado pelos autores.

A Tabela 11 abaixo ilustra a energia metabolizável nas misturas energética e proteica.

Tabela 11. Energia metabolizável nas misturas energética e proteica

\begin{tabular}{lcccc}
\hline Mistura Energética & EM (kcal/kg) & \% Alimento & Cálculo & Resultado PB (\%) \\
\hline Milho & 3.493 & 69,99 & $\begin{array}{c}3.493^{*} \\
(69,99 / 100)\end{array}$ & $2.444,75$ \\
Farinha de trigo & 2.103 & 7,78 & $\begin{array}{c}2.103^{*} \\
(7,78 / 100)\end{array}$ & 163,61 \\
Subtotal & - & - & - & $\mathbf{2 . 6 0 8 , 3 6}$ \\
\hline Mistura Proteica & EM (kcal/kg) & \% Alimento & Cálculo & PB (\%) \\
\hline Farinha de soja & 3.378 & 15,85 & $\begin{array}{c}3.378^{*} \\
(15,85 / 100)\end{array}$ & 535,41 \\
Farinha de carne & 2.133 & 1,29 & $\begin{array}{c}2.133^{*} \\
(1,29 / 100)\end{array}$ & 27,52 \\
Farinha de sangue & 2.809 & 1,29 & $\begin{array}{c}2.809^{*} \\
(1,29 / 100)\end{array}$ & 36,24 \\
\hline
\end{tabular}




\begin{tabular}{llllc}
\hline Subtotal & - & - & - & 599,17 \\
\hline Total & - & - & - & $3.207,53$
\end{tabular}

Fonte: Elaborado pelos autores.

A distribuição de lisina nas misturas energética e proteica está contemplada pela Tabela 12 .

Tabela 12. Distribuição de lisina nas misturas energética e proteica

\begin{tabular}{lcccc} 
Mistura Energética & Lis. (\%) & $\begin{array}{c}\% \\
\text { Alimento }\end{array}$ & Cálculo & $\begin{array}{c}\text { Resultado Lisina } \\
\text { (\%) }\end{array}$ \\
\hline Milho & 0,23 & 69,99 & $\begin{array}{c}0,23^{*} \\
(69,99 / 100)\end{array}$ & 0,1610 \\
Farinha de trigo & 0,57 & 7,78 & $0,57^{*}(7,78 / 100)$ & 0,0443 \\
Subtotal & - & - & - & $\mathbf{0 , 2 0 5 3}$ \\
\hline Mistura Proteica & PB (\%) & $\begin{array}{c}\% \\
\text { Alimento }\end{array}$ & Cálculo & $\begin{array}{c}\text { Resultado Lisina } \\
\text { (\%) }\end{array}$ \\
\hline Farinha de soja & 2,87 & 15,85 & $\begin{array}{c}2,87^{*} \\
(15,85 / 100)\end{array}$ & 0,4549 \\
Farinha de carne & 2,28 & 1,29 & $2,28^{*}(1,29 / 100)$ & 0,0294 \\
Farinha de sangue & 6,57 & 1,29 & $6,57^{*}(1,29 / 100)$ & 0,0848 \\
\hline Subtotal & - & - & - & $\mathbf{0 , 5 6 9 1}$ \\
\hline Total & - & - & - & $\mathbf{0 , 7 7 4 4}$ \\
\hline
\end{tabular}

Fonte: Elaborado pelos autores.

Em última análise, faz-se necessário registrar que as Tabelas e Figura contemplados nessa seção ilustraram de forma paulatina o processo de formulação da ração, a qual apresentou o custo de $\mathrm{R} \$ 0,48$ por quilograma de alimento, conforme pode ser observado na Tabela 13 lançada abaixa.

Quadro 13. Quadro sintético envolvendo ingredientes, preço e custo do alimento por quilograma

(continua)

\begin{tabular}{lccc}
\hline Ingrediente & Preço $(\mathbf{R} \mathbf{S} / \mathbf{K g})$ & Alimento $(\mathbf{K g})$ & $\begin{array}{c}\text { Custo do } \\
\text { Alimento(R\$/Kg) }\end{array}$ \\
\hline Milho & 0,290 & 0,700 & 0,203 \\
Farinha de trigo & 0,320 & 0,078 & 0,025 \\
Farinha de soja & 0,670 & 0,159 & 0,106
\end{tabular}


(conclusão)

$\begin{array}{lccc}\text { Farinha de carne } & 1,20 & 0,013 & 0,015 \\ \text { Farinha de sangue } & 1,440 & 0,013 & 0,019 \\ \text { Sal } & 0,480 & 0,005 & 0,002 \\ \text { Mistura Mineral } & 4,480 & 0,001 & 0,004 \\ \text { Mistura Vitamínica } & 23,200 & 0,001 & 0,023 \\ \text { Fosfato bicálcico } & 2,320 & 0,005 & 0,011 \\ \text { Calcário Calcítico } & 0,130 & 0,008 & 0,001 \\ \text { Óleo de soja }(* 900 & 4,000 & 0,018 & 0,071 \\ \mathrm{~mL}) & & \end{array}$

Total

$\mathbf{0 , 4 8 0}$

Fonte: Elaborado pelos autores.

A próxima seção abordará as considerações finais do presente estudo.

\section{CONSIDERAÇÕES FINAIS}

O tomador de decisão, por ocasião da implementação da referida dieta, deverá ter em mente de que está tratando de um sistema dinâmico, em que os insumos são afetados o tempo todo por variáveis micro e macro-econômicas, variáveis regionais, etc. Algumas variáveis são difíceis de modelar, o que certamente exigirá que o gestor esteja aberto a novas possibilidades. Assim sendo, o modelo sugerido acima poderá funcionar razoavelmente bem dentro de uma janela temporal relativamente pequena, por mais robusto que ele seja.

Para Zardo e Lima (1999, p. 16), os microminerais participam, de modo geral, como parcela componente de sistemas enzimáticos em uma sucessão de processos metabólicos essenciais. Na formulação de ração para suínos, deve-se dedicar atenção ao cálcio, fósforo, sódio, manganês, selênio, ferro, zinco, cobre e iodo.

Adicionalmente, no que tange à lisina, componente da ração suína, convém trazer à baila estudo dos autores citados anteriormente. Zardo e Lima (1999, p. 17) afirmam que a proteína da alfafa possui um bom balanceamento de aminoácidos, com um razoável teor de lisina. Contudo, sua digestibilidade é baixa, com valor próximo a $60 \%$. Existem dificuldades na disponibilização de níveis adequados de 
energia em dietas com alfafa, já que a capacidade de consumo de alimentos pelos suínos é restrita. A alfafa é rica em vitaminas A, E e K, tem elevado teor de cálcio e baixo de fósforo. É recomendada para animais adultos, especialmente para porcas em gestação. Para as fases iniciais, o emprego não é recomendado e para crescimento, terminação e lactação, a disponibilização deve ser em níveis limitados. A alfafa apresenta taninos, que são elementos antinutricionais, que impactam na ação das enzimas diminuindo a digestibilidade dos nutrientes, além de reduzir a palatabilidade do alimento.

Faz-se necessário destacar que a presente pesquisa não contemplou questões subjetivas, tais como a palatabilidade dos insumos utilizados na ração. Nesse contexto, o problema deixa de ter um caráter eminentemente quantitativo, onde cada alimento possui um valor nutricional e um custo unitário, desejandose obter uma dieta de custo mínimo. Passa-se a ter outras questões subjacentes que necessitarão da avaliação de uma equipe multidisciplinar lançando mão de ferramentas da Pesquisa Operacional Soft, questões essas as quais os autores recomendam a observância por ocasião da condução de pesquisas futuras.

\section{REFERÊNCIAS}

ALMEIDA, L. J.; MARTINS, G. A. S.; SILVA, W. G. Otimização de processos utilizando a programação linear. Enciclopédia Biosfera, v. 09, p. 1641-1653, 2013.

ALVES, R. B. Importância da PSE na carne de suínos. 2007. Monografia. (Especialização em Higiene e Inspeção de Produtos de Origem Animal) - Universidade Castelo Branco, Brasília, 2007.

ANUALPEC. Anuário da Pecuária Brasileira, 2002.

BELLAVER, C.; LUDKE, J. V. Considerações sobre os alimentos alternativos para dietas de suínos. Palestra apresentada no ENIPEC em 09-03-2004. Cuiabá, 2004.

CLÍMACO, J. N.; ANTUNES, C. H.; ALVES, M. J. Programação Linear Multiobjectivo. Coimbra: Imprensa da Universidade, 2003. 
CORRAR, L. J.; THEÓPHILO, C. R.; BERGMANN, D. R. Programação Linear. In: CORRAR, L. J.; THEÓPHILO, C. R. (Org.). Pesquisa Operacional para Decisão em Contabilidade e Administração. 2. ed. São Paulo: Atlas, 2004, v. 1, p. 331-393.

EMBRAPA. Centro Nacional de Pesquisa de Suínos e Aves. Ministério da Agricultura e do Abastecimento. 2011. Disponível em: < http://sistemasdeproducao.cnptia. embrapa.br/FontesHTML/Suinos/SPSuinos/nutricao.html> Acesso em: 14 jun. 2013.

FARIAS, E. R. Seleção de cultura agrícola para o plantio. Aulas de Pesquisa Operacional. Universidade Católica de Pernambuco. Recife, 2013.

FÁVERO, J. A. et al. Produção Suínos. Embrapa Suínos e Aves. Versão eletrônica. Jan. 2003. Disponível em: < http://sistemasdeproducao.cnptia.embrapa.br/FontesHTML/ Suinos/SPSuinos/nutricao.html > Acesso em: 12 jan. 2015.

FERREIRA, R. A. Efeitos do clima sobre a nutrição de suínos. 2009. Disponível em: <http://www.cnpsa.embrapa.br/abraves-sc/pdf/Memorias2000/1_RonyFerreira. pdf $>$ Acesso em: 14 jun. 2013.

FERREIRA, R. A. Efeitos do clima sobre a nutrição de suínos. In: ENCONTROS TÉCNICOS DA ABRAVES-SC, 2000, Chapecó. Memórias 2000. Anais... Chapecó, 2000. v. 1, p. 01-15.

GETIRANA, A. C. V. Análise de soluções de conflitos pelo uso da água no setor agrícola através de técnicas de programação linear. 2005. Dissertação. (Mestrado em Engenharia Civil) - Universidade Federal do Rio de Janeiro, Rio de Janeiro, 2005.

GIROTTO, A. F. Custo médio de produção de suínos para abate. Comunicado Técnico da EMBRAPA, Anexo 35, março, 1989.

GONÇALVES, R. G.; PALMEIRA, E. M. Suinocultura brasileira. Observatório de la Economia Latinoamericana, n. 71, p. 01-11, 2006.

LAVANDOSCKI, T. R. Avaliação do desempenho de suínos nas fases de crescimento e terminação, submetidos a diferentes níveis nutricionais. 2007. Monografia (Trabalho de Conclusão de Curso em Agronomia) - Universidade Federal 
de Santa Catarina, Florianópolis, 2007.

MARCATO, S. M.; LIMA, G. J. M. M. Efeito da retirada da suplementação de microminerais e fibra sobre a composição e quantidade das fezes e urinas excretadas pelos suínos em crescimento. Revista da Faculdade de Zootecnia, Veterinária e Agronomia (PUCRS), Uruguaiana, v. 13, n. 1, p. 28-41, 2006.

MAYNARD, L. A.; LOOSLI, J. K. Nutrição animal. 3. ed. São Paulo: Freitas Bastos, 1984.

MENON, M. H. Meta-heurísticas na otimização do sortimento florestal. 2005. Tese (Doutorado Ciências Florestais) - Universidade Federal do Paraná, Curitiba, 2005.

ROPPA, L. Tendências da suinocultura mundial e as oportunidades brasileiras. Anuário da Pecuária Brasileira, São Paulo, p. 281-284, 2002.

XAVIER, O. M. A origem da Teoria dos Jogos e a existência de equilíbrio em Nash. 2013. Monografia (Trabalho de Conclusão de Curso0 - Faculdade de Ciências Econômicas. Universidade Federal do Rio Grande do Sul, Porto Alegre, 2013.

ZANOTTO, D. L. Nutrição é melhor com granulometria correta. Revista Alimentação Animal, São Paulo, v. 14, 30 maio 1999.

ZARDO, A. O.; LIMA, G. J. M. M. Alimentos para suínos. Boletim Informativo de Pesquisa: EMBRAPA Suínos e Aves e Extensão. Concórdia, 1999. 71p. Disponível em: <http://file.aviculturaindustrial.com.br/Material/Tecnico/alimentosuino.pdf> Acesso em: 12 jan. 2015.

Recebido em: 08 de setembro de 2014 Aceito em: 19 de maio de 2015

${ }^{1}$ A versão preliminar do artigo foi aprovada no XXXIV Encontro Nacional de Engenharia de Produção (ENEGEP) 